\title{
Speech Disorder
}

National Cancer Institute

\section{Source}

National Cancer Institute. Speech Disorder. NCI Thesaurus. Code C5041.

A term referring to disorders characterized by the disruption of normal speech. It includes stuttering, lisps, dysarthria and voice disorders. 